\title{
Proportioning Design of Foamed Concrete Mixed with Recycled Micro- powder of Construction Waste
}

\author{
Hongyang Xie ${ }^{1}$, Jianjun Dong ${ }^{1 *}$, Yong Deng ${ }^{1}$,Yiwen Dai ${ }^{1}$, Mingwei Deng ${ }^{2}$ \\ ${ }^{1}$ School of Civil Engineering and Architecture, Nanchang Aviation University, Nanchang 330000, Jiangxi, China \\ ${ }^{2}$ Practical Training Department, Jiangxi Construction Vocational and Technical College, Nanchang 330000, Jiangxi, China \\ Email: 3297826491@qq.com
}

\begin{abstract}
This paper presents a new kind of foamed concrete mixed with recycled micro-powder of construction waste which is helpful for saving resources, protecting the environment and achieving a sustainable development. An orthogonal experiment was designed to test the compressive strength of foamed concrete relatng to different factors, and the degree of influence were studied according to test result and range analysis of the factors. Using the efficacy coefficient method, the best mixture ratio was derived when both requirements of a quite light weight and a high strength were satisfied. XRD and SEM tests showed that the increase in compressive strength was due to the refinement of pores within the foamed concrete by the addition of recycled micronized powder.

Keywords: construction waste recycled micronized powder, orthogonal test, foam concrete, efficacy coefficient method, SEM test
\end{abstract}

\section{Introduction}

In China, how to deal with the growing amount of construction waste has become a critical environmental problem. Commonly, construction waste is transported to suburbs for simple landfill without any treatment, which not only occupies vast land, but also becomes a potential source of pollution. On the other hand, the rapid development of the construction industry has led to wide shortage of sand and gravel. The idea of recycling construction waste is an optional approach to alleviate the problem ${ }^{[1]}$.

Foam concrete is a lightweight material consisting of a silicate cement paste or cement filler matrix (mortar) with a uniform void or pore structure by introducing air in the form of small bubbles. In recent years, foam concrete has been widely used in the field of geotechnical engineering ${ }^{[2]}$. However, the large amount of cementing material and the relatively expensive cost hinder its promotion in reality ${ }^{[3]}$. Also, foam concrete is widely used as a filler material in non-structural members. In this paper, construction waste is adopted to produce recycled micronized powder which is introduced to foam concrete, and the compressive strength of foamed concrete is tested according to orthogonal experiment principles.

\section{Experimental overview}

\subsection{Test raw materials}

\subsubsection{Cement}

Nanchang Conch P.O. 42.5 ordinary silicate cement is adopted in this experiment, and the basic properties of the cement are shown below.

Table 1. Basic properties of cement

\begin{tabular}{cccc}
\hline Projects & Indicators & Results & Judgment \\
\hline Initial setting time(min) & $\geq 60$ & 176 & Qualified \\
Final setting time (min) & $\leq 600$ & 310 & Qualified \\
3d flexural strength (Mpa) & $\geq 3.5$ & 4.2 & Qualified \\
28d flexural strength(Mpa) & $\geq 6.5$ & 7.1 & Qualified \\
3d compressive strength (Mpa) & $\geq 17$ & 22.3 & Qualified \\
28d compressive strength (Mpa) & $\geq 42.5$ & 48.2 & Qualified \\
\hline
\end{tabular}


Table 2. Chemical composition of cement

\begin{tabular}{ccccccc}
\hline Ingredients & $\mathrm{SiO}_{2}$ & $\mathrm{Fe}_{2} \mathrm{O}_{3}$ & $\mathrm{Al}_{2} \mathrm{O}_{3}$ & $\mathrm{CaO}$ & $\mathrm{MgO}$ & $\mathrm{SO}_{3}$ \\
\hline Content $(\%)$ & 22 & 42 & 52 & 63 & 1.5 & 2.2 \\
\hline
\end{tabular}

\subsubsection{Construction waste recycled micronized powder}

Provided by Jiangxi Institute of Transportation Science, it was obtained from the waste concrete generated from cement pavement after crushing and grinding. The XRD images of the recycled micro powder of construction waste are shown below.

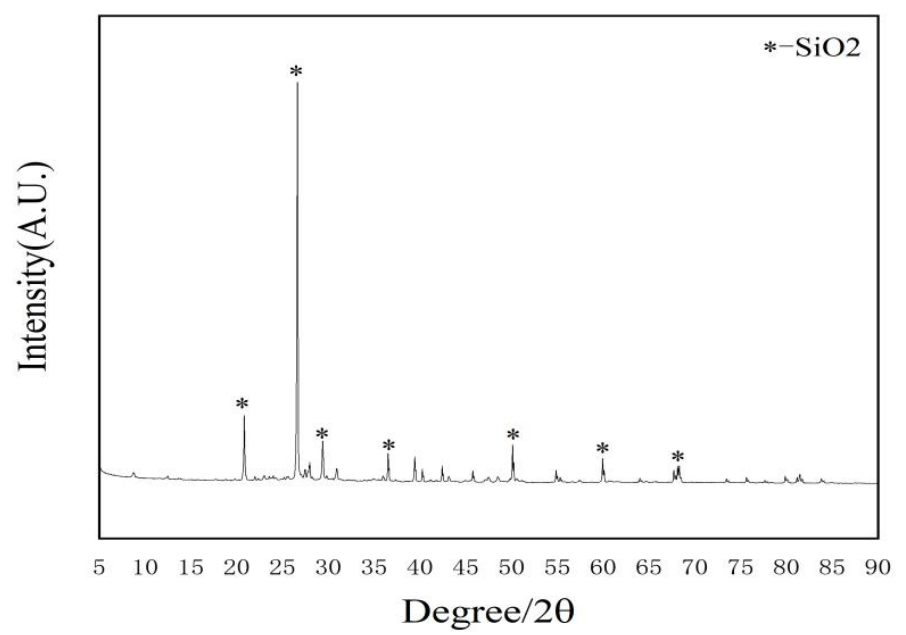

Figure 1. XRD pattern of recycled construction waste micronized powder As shown above, the main component of the micronized powder is $\mathrm{SiO}_{2}$.

\subsubsection{Foaming agent}

Foaming agents have an important influence on the performance of foam concrete. In this experiment, 6018 surfactant, animal protein-based blowing agent, plant protein-based blowing agent, composite blowing agent and sodium dodecyl sulfate ${ }^{[4]}$ were selected for the performance test of blowing agent.

Different types of foaming agents were diluted with water to form foaming solution, pressurized and foamed through the air of cement foaming machine, and then tested for water secretion and settlement distance. Finally HT compound foaming agent produced by Henan Huatai Building Material Company is adopted and the best effect is achieved by diluting the foaming agent 30 times. Its physical performance index is shown in the table below.

Table 3. HT compound foaming agent physical property index

\begin{tabular}{cccccccc}
\hline \multirow{2}{*}{$\begin{array}{c}\text { Indicator } \\
\text { Results }\end{array}$} & $\begin{array}{c}\text { Appearance } \\
\text { color }\end{array}$ & Density & Solids content & PH value & Foaming times & $\begin{array}{c}1 \mathrm{~h} \mathrm{settling} \\
\text { distance/mm }\end{array}$ & $\begin{array}{c}1 \mathrm{~h} \text { water } \\
\text { secretion rate/\% }\end{array}$ \\
\cline { 2 - 7 } & Dark brown & $1.05\left(\mathrm{~g} / \mathrm{cm}^{3}\right)$ & $23.8 \%$ & 9.2 & $15 \sim 30$ & $\leq 50$ & $\leq 70$ \\
\hline
\end{tabular}

\subsection{Matching ratio design}

At present, there is no corresponding standard and specification for foam concrete in China, and the relevant calculation lacks a unified standard. With reference to domestic and foreign literature, the formula for calculating the ratio of recycled micronized foam concrete with construction waste is obtained by expanding on the basis of the method for designing the ratio of recycled foam concrete with fly ash solid waste proposed by Li Yingquan ${ }^{[5]}$.

$$
\begin{gathered}
\rho_{d y}=S_{\mathrm{a}}\left(M_{c}+M_{g z}\right) \\
M_{w}=\phi\left(M_{c}+M_{g z}\right)
\end{gathered}
$$


Where $\rho_{d r y}$ is the dry density. $S_{a}$ is a factor of 1.2 in case of ordinary silicate cement and 1.4 in case of sulfo-aluminate cement. $M_{c}, M_{g z}, M_{w}$ are cement dosage, solid waste recycled fine aggregate dosage and water dosage respectively. $\varphi$ is the ratio of water to material.

$$
\begin{gathered}
V_{1}=\frac{M_{g z}}{\rho_{g z}}+\frac{M_{c}}{\rho_{c}}+\frac{M_{w}}{\rho_{w}} \\
V_{2}=K\left(1-V_{1}\right)
\end{gathered}
$$

$\rho_{c}, \rho_{g z}, \rho_{w}$ are the density of solid waste recycled fine aggregate, cement density, and water density, whose values are $3547 \mathrm{~kg} / \mathrm{m}^{3}, 3100 \mathrm{~kg} / \mathrm{m}^{3}$, and $1000 \mathrm{~kg} / \mathrm{m}^{3}$, respectively. $V_{1}, V_{2}$ is the total volume of slurry and the amount of foam added. $K$ is a factor, generally taken as 1.1 to 1.3 .

$$
\begin{gathered}
M_{y}=V_{2} \beta_{b} \\
M_{p}=M_{y} /(\beta+1)
\end{gathered}
$$

Where $M_{y}$ is the quality of foam liquid formed. $\beta_{b}$ is the actual measured foam density. And $M_{p}, \beta$ are the foam agent mass and foam agent dilution times respectively.

\subsection{Test block preparation and test method}

Calculate the content of each component first, then accurately weigh the amount of cement, construction waste micronized powder and hydroxypropyl methylcellulose ether (HPMC), then dry mix with a mixer for 150s;

accurately weigh the mass of water, add it to the mixer and mix for $150 \mathrm{~s}$.

add the aqueous solution of foaming agent into the cement foam all-in-one machine, pressurize the foam by air, quickly add it into the construction waste cement slurry after accurately measuring the volume of foam, and stir for $120 \mathrm{~s}$, when the mixing is uniform and no bubbles float on the surface of the slurry, immediately conduct the flow test, after the test meets the requirements of $160-200 \mathrm{~mm}$, quickly pour it into the mold and lightly turn the mold upside down to prevent the resulting test block Irregular;

after $36 \mathrm{~h}$ resting scrape the surface of the mold and remove the mold with an air gun, and then store in a standard maintenance room with temperature $20 \pm 2 \mathrm{C}$ and humidity above $95 \%$, and maintain $28 \mathrm{~d}$.

The measurement of dry density of recycled micronized foam concrete from construction waste was implemented according to the industry standard JGT266-2011 "Foam Concrete" of the People's Republic of China ${ }^{[6]}$; the compressive strength of recycled micronized foam concrete from construction waste was referred to GB/T50081-2002 "Standard for Mechanical Properties Test Methods of Ordinary Concrete" and GB/T11969-2008 [7].

\subsection{Design of orthogonal test}

The orthogonal design method is applied to deal with multi-factor test ${ }^{[8]}$. With this method only a small number of tests can reach the correct judgment. Here in the orthogonal test, 4 factors(the amount of recycled construction waste micronized powder, water to material ratio, foam dosing, and HPMC dosing) and 5 levels are selected, and the orthogonal test table is L25 $\left(4^{5}\right)$. The specific factor level is shown in Table 4.

Table 4. Factor levels of orthogonal tests

\begin{tabular}{ccccc}
\hline & \multicolumn{3}{c}{ Factors } \\
\cline { 2 - 5 } Level & Foam dosing(A) & $\begin{array}{c}\text { Construction waste recycled } \\
\text { micronized powder dosing(B) }\end{array}$ & Water to material ratio(C) & HPMC dosing(D) \\
\hline 1 & $3 \%$ & $10 \%$ & 0.45 & $0.03 \%$ \\
3 & $4 \%$ & $20 \%$ & 0.5 & $0.04 \%$ \\
4 & $5 \%$ & $30 \%$ & $0.65 \%$ & $0.06 \%$ \\
5 & $6 \%$ & $40 \%$ & 0.65 & $0.07 \%$ \\
\hline
\end{tabular}




\section{Experimental results}

\subsection{The results of the orthogonal tests are shown in Table 5}

According to the orthogonal test results of regenerated micronized powder in Table 5, the compressive strength was subjected to extreme difference analysis, and the results are shown in Table 6.

Table 6 calculates the extreme difference value of each level of each factor of the orthogonal test, the size of the extreme difference value reflects the influence of each factor on the compressive strength to some extent. It can be concluded from the table that the foam admixture has the greatest influence on the compressive strength of recycled micronized foam concrete.

Table 5. Results of orthogonal test for recycled micronized foam concrete

\begin{tabular}{|c|c|c|c|c|c|c|}
\hline Group number & A & B & $\mathrm{C}$ & $\mathrm{D}$ & Dry Density $\left(\mathrm{kg} / \mathrm{m}^{3}\right)$ & $28 \mathrm{~d}$ compressive strength $(\mathrm{Mpa})$ \\
\hline $1^{*}$ & 1 & 1 & 1 & 1 & 1243.75 & 6.09 \\
\hline $2^{*}$ & 1 & 2 & 2 & 2 & 1021.95 & 4.40 \\
\hline $3^{*}$ & 1 & 3 & 3 & 3 & 909.75 & 3.13 \\
\hline $4^{*}$ & 1 & 4 & 4 & 4 & 1018.50 & 4.06 \\
\hline $5^{*}$ & 1 & 5 & 5 & 5 & 903.95 & 2.68 \\
\hline $6^{*}$ & 2 & 1 & 2 & 3 & 984.30 & 3.22 \\
\hline $7^{*}$ & 2 & 2 & 3 & 4 & 948.55 & 4.37 \\
\hline $8^{*}$ & 2 & 3 & 4 & 5 & 1049.35 & 5.58 \\
\hline $9^{*}$ & 2 & 4 & 5 & 1 & 648.75 & 1.15 \\
\hline $10^{*}$ & 2 & 5 & 1 & 2 & 720.70 & 0.95 \\
\hline $11^{*}$ & 3 & 1 & 3 & 5 & 955.85 & 4.17 \\
\hline $12^{*}$ & 3 & 2 & 4 & 1 & 904.65 & 2.71 \\
\hline $13^{*}$ & 3 & 3 & 5 & 2 & 907.20 & 2.31 \\
\hline $14^{*}$ & 3 & 4 & 1 & 3 & 739.50 & 1.82 \\
\hline $15^{*}$ & 3 & 5 & 2 & 4 & 845.90 & 1.64 \\
\hline $16^{*}$ & 4 & 1 & 4 & 2 & 833.40 & 2.74 \\
\hline $17^{*}$ & 4 & 2 & 5 & 3 & 845.70 & 2.48 \\
\hline $18^{*}$ & 4 & 3 & 1 & 4 & 805.90 & 1.49 \\
\hline $19^{*}$ & 4 & 4 & 2 & 5 & 716.65 & 2.12 \\
\hline $20^{*}$ & 4 & 5 & 3 & 1 & 698.40 & 1.19 \\
\hline $21^{*}$ & 5 & 1 & 5 & 4 & 895.30 & 2.29 \\
\hline $22^{*}$ & 5 & 2 & 1 & 5 & 701.85 & 1.15 \\
\hline $23^{*}$ & 5 & 3 & 2 & 1 & 689.55 & 0.75 \\
\hline $24^{*}$ & 5 & 4 & 3 & 2 & 886.45 & 1.73 \\
\hline $25^{*}$ & 5 & 5 & 4 & 3 & 681.20 & 1.51 \\
\hline
\end{tabular}


Table 6. Table of extreme difference analysis of compressive strength of recycled micronized foam concrete

\begin{tabular}{|c|c|c|c|c|}
\hline & Foam dosing & $\begin{array}{l}\text { Construction waste recycled } \\
\text { micronized powder dosing }\end{array}$ & Water to material ratio & HPMC dosing \\
\hline $\mathrm{K} 1$ & 4.072 & 3.702 & 2.300 & 2.378 \\
\hline $\mathrm{K} 2$ & 3.054 & 3.022 & 2.426 & 2.426 \\
\hline $\mathrm{K} 3$ & 2.530 & 2.652 & 2.918 & 2.432 \\
\hline K5 & 1.486 & 1.594 & 2.182 & 3.140 \\
\hline Extreme difference value $\mathrm{R}$ & 2.586 & 2.108 & 1.138 & 0.762 \\
\hline ranking & 1 & 2 & 3 & 4 \\
\hline
\end{tabular}

The requirements of the two indicators, dry density and compressive strength, are often contradictory. It is hard to achieve both light weight and high strength. In this paper, the efficacy coefficient method is used to calculate the efficacy coefficient and total efficacy coefficient of these two indicators, as shown in Table 7.

From Table 7, it can be concluded that the total efficacy coefficient of the test block under $8^{*}$ group matching ratio is the largest, so the level of recycled micronized foam concrete that meets the requirement of light weight and high strength is $\mathrm{A}_{2} \mathrm{~B}_{3} \mathrm{C}_{4} \mathrm{D}_{5}$, that is, the optimal matching ratio is $4 \%$ foam admixture, $30 \%$ construction waste recycled micronized powder admixture, 0.6 water to material ratio and $0.07 \%$ HPMC admixture.

Table 7. Table of efficacy factor of recycled micronized foam concrete

\begin{tabular}{|c|c|c|c|c|c|}
\hline \multirow{2}{*}{$\begin{array}{l}\text { Group } \\
\text { number }\end{array}$} & \multicolumn{2}{|c|}{ Study Objectives } & \multicolumn{2}{|c|}{ Efficacy factor } & \multirow{2}{*}{$\begin{array}{l}\text { Total efficacy factor } \\
\qquad d=\sqrt[2]{d_{1} d_{2}}\end{array}$} \\
\hline & Dry Density $\left(\mathrm{kg} / \mathrm{m}^{3}\right)$ & $\begin{array}{l}\text { 28d compressive } \\
\text { strength(Mpa) }\end{array}$ & Dry Density d ${ }_{1}$ & $\begin{array}{l}\text { 28d compressive strength } \\
\qquad \mathrm{d}_{2}\end{array}$ & \\
\hline $1^{*}$ & 1243.75 & 6.09 & 0.52 & 1.00 & 0.72 \\
\hline $2^{*}$ & 1021.95 & 4.40 & 0.63 & 0.72 & 0.67 \\
\hline $3^{*}$ & 909.75 & 3.13 & 0.71 & 0.51 & 0.60 \\
\hline $4^{*}$ & 1018.50 & 4.06 & 0.64 & 0.67 & 0.65 \\
\hline $5^{*}$ & 903.95 & 2.68 & 0.72 & 0.44 & 0.56 \\
\hline $6^{*}$ & 984.30 & 3.22 & 0.66 & 0.53 & 0.59 \\
\hline $7^{*}$ & 948.55 & 4.37 & 0.68 & 0.72 & 0.70 \\
\hline $8^{*}$ & 1049.35 & 5.58 & 0.62 & 0.92 & 0.76 \\
\hline $9^{*}$ & 648.75 & 1.15 & 1.00 & 0.19 & 0.44 \\
\hline $10^{*}$ & 720.70 & 0.95 & 0.90 & 0.16 & 0.38 \\
\hline $11^{*}$ & 955.85 & 4.17 & 0.68 & 0.68 & 0.68 \\
\hline $12^{*}$ & 904.65 & 2.71 & 0.72 & 0.44 & 0.56 \\
\hline $13^{*}$ & 907.20 & 2.31 & 0.72 & 0.38 & 0.52 \\
\hline $14^{*}$ & 739.50 & 1.82 & 0.97 & 0.30 & 0.54 \\
\hline $15^{*}$ & 845.90 & 1.64 & 0.77 & 0.27 & 0.46 \\
\hline $16^{*}$ & 833.40 & 2.74 & 0.78 & 0.45 & 0.59 \\
\hline $17^{*}$ & 845.70 & 2.48 & 0.77 & 0.41 & 0.56 \\
\hline $18^{*}$ & 805.90 & 1.49 & 0.81 & 0.24 & 0.44 \\
\hline $19^{*}$ & 716.65 & 2.12 & 0.91 & 0.35 & 0.56 \\
\hline $20^{*}$ & 698.40 & 1.19 & 0.93 & 0.20 & 0.43 \\
\hline $21^{*}$ & 895.30 & 2.29 & 0.72 & 0.38 & 0.52 \\
\hline $22^{*}$ & 701.85 & 1.15 & 0.92 & 0.19 & 0.42 \\
\hline $23^{*}$ & 689.55 & 0.75 & 0.94 & 0.12 & 0.34 \\
\hline $24^{*}$ & 886.45 & 1.73 & 0.73 & 0.28 & 0.45 \\
\hline $25^{*}$ & 681.20 & 1.51 & 0.95 & 0.25 & 0.49 \\
\hline
\end{tabular}




\subsection{Analysis and discussion of the level of influencing factors}

The laws of the effect of each factor on the strength of recycled micronized foam concrete are shown in Figure 2 to Figure 5 .

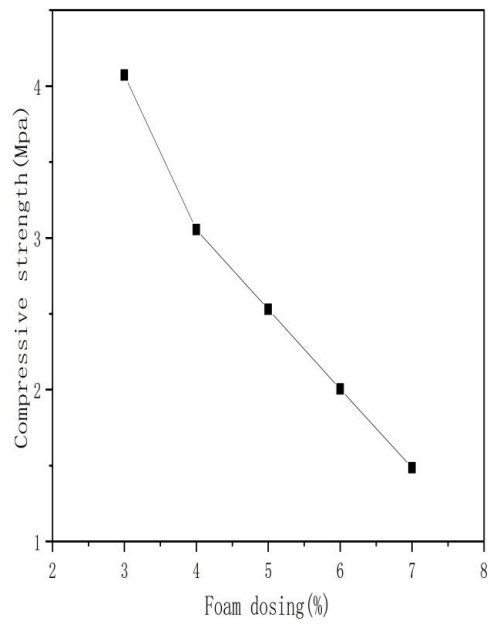

Figure 2. Variation curve of compressive strength with the amount of foam dosing

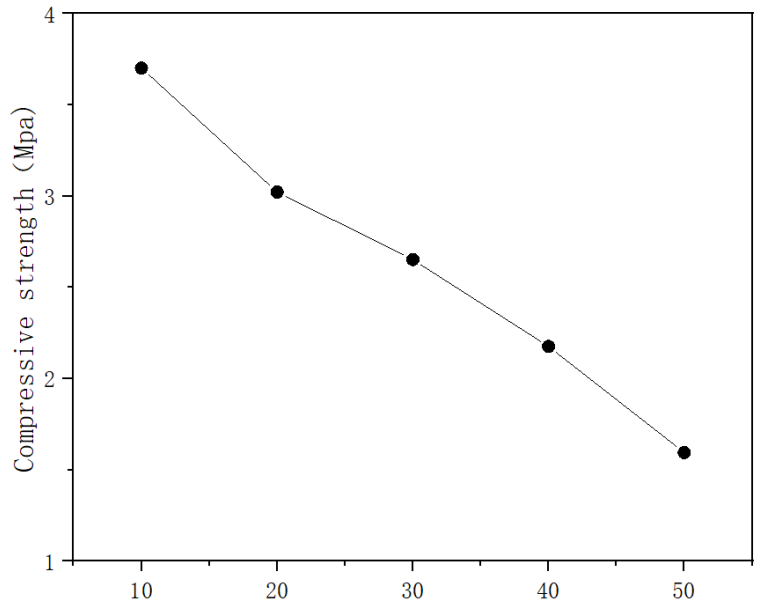

Construction waste recycled micronized powder dosing $(\%)$

Figure 3. Variation curve of compressive strength with the amount of recycled

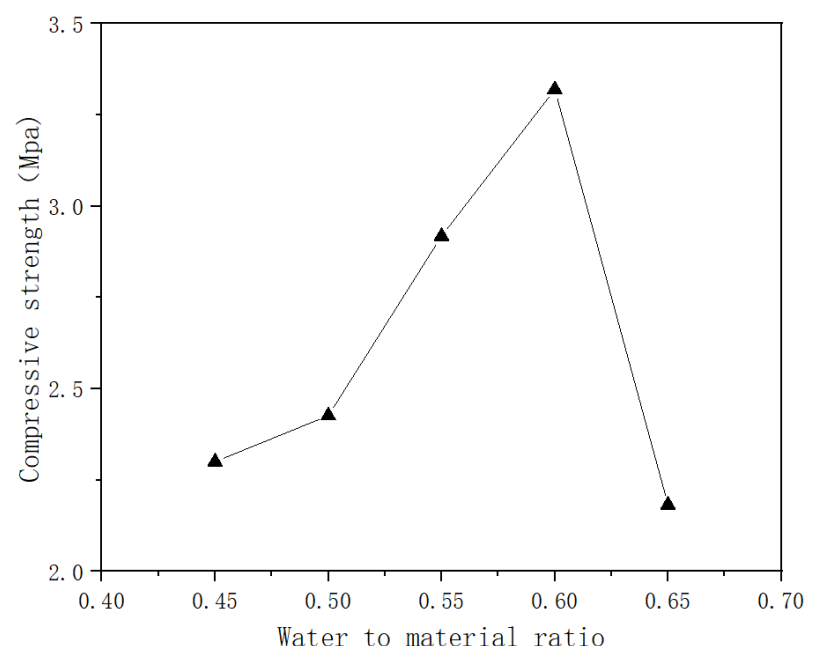

Figure 4. Variation curve of compressive strength with water to material ratio 


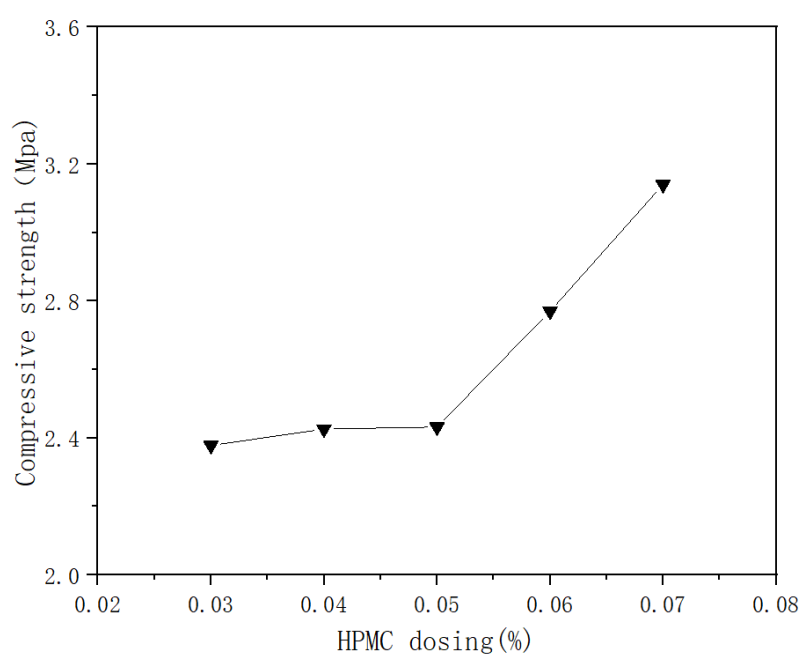

Figure 5. Variation curve of compressive strength with HPMC dosing

From Figure 2, it can be seen that with the increase of foam admixture from 3\% to $7 \%$, the compressive strength of recycled micronized foam concrete decreases from $4.072 \mathrm{MPa}$ to $1.486 \mathrm{MPa}$, showing a general decreasing trend, and the minimum value of $1.486 \mathrm{MPa}$ is obtained at $7 \%$ of foam admixture, which shows that the increase of foam admixture has a significant effect on the reduction of compressive strength of recycled micronized foam concrete. The main reasons are: first, the increase of foam dosing is accompanied by the decrease of cementitious material, which is the main source of strength of recycled micronized foam concrete; second, the increase of foam dosing will lead to the increase of pore volume and will produce a large number of harmful pores, which makes the internal pore distribution of the specimen uneven and leads to the decrease of strength.

As can be seen from Figure 3, the compressive strength of recycled micronized foam concrete decreases from 3.702 $\mathrm{MPa}$ to $1.594 \mathrm{MPa}$ when the admixture of recycled micronized construction waste increases from $10 \%$ to $50 \%$, and the overall trend is a gradual decrease. This is due to the following reasons: first, the amount of silicate cement is reduced, resulting in part of the recycled micronized powder does not form a skeleton dense type, and the strength is reduced; second, the foam liquid film is subjected to increased extrusion pressure, resulting in its increased water secretion, and the foam ruptures before the initial setting of the cementitious material, forming harmful large pores and decreasing the strength. Third, the main component of regenerated micronized powder is glassy $\mathrm{SiO}_{2}$, which is an inert material, and the increase of substitution rate will make the strength decrease.

From Figure 4, it can be seen that when the water-to-material ratio increases from 0.45 to 0.65 , the compressive strength of recycled micronized foam concrete decreases from $2.300 \mathrm{MPa}$ to $2.182 \mathrm{MPa}$, with an overall trend of rising and then decreasing. The reasons are as follows: $i$. When the water-to-material ratio is from 0.45 to 0.60 , its compressive strength increases with the increase of water-to-material ratio, because the recycled micro powder of construction waste contains cement particles that are not completely hydrated, which makes the water required more than the virgin material. The more water is added, the more complete the hydration reaction is, the denser the internal structure of recycled micronized foam concrete is, and the higher the strength is. Second, when the water-cement ratio is $0.60 \sim 0.65$, its compressive strength decreases instead with the increase of water-material ratio, mainly because: (1) too much water, due to the different density, resulting in the regenerated micro powder in the denser components stay below, the foam and the remaining cementitious materials on top, leading to the delamination; second, too much water is added to thicken the foam liquid film, which will secrete water faster under the action of gravity, resulting in the foam premature rupture or the formation of a large number of harmful holes, reducing the strength.

As can be seen from Figure 5, with the increase of HPMC admixture, the compressive strength of recycled micronized foam concrete increased from 2.378 MPa to 3.140 MPa, showing an overall upward trend. The reasons are as follows: with the increase of HPMC admixture, the foam performance is improved, the content of foam destroyed during the mixing process is reduced, and it makes the foam more uniformly distributed in the slurry, the harmful pores in the formed specimens are reduced and the dense pores are increased, the shape, spacing and diameter of the pores are improved, and the strength is increased. 


\section{Microscan analysis}

\subsection{XRD test}

The $8^{*}$ group specimens were crushed and ground for XRD test, and the XRD results of plain foam concrete were taken as a control. The results are shown below.

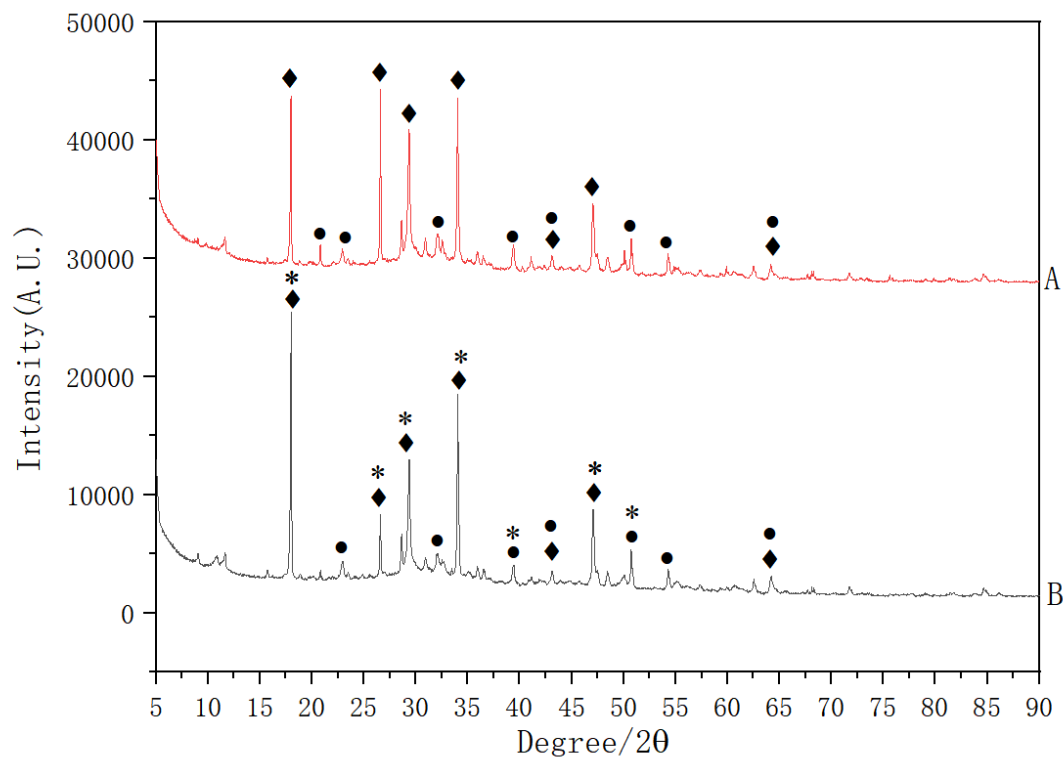

Figure 6. XRD patterns of plain foam concrete and recycled micronized foam concrete

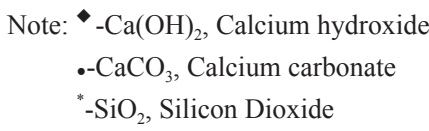

Sample A is ordinary foam concrete and sample B is recycled micronized foam concrete. As can be seen from the above figure, the positions of the peaks of the two samples are almost the same, which shows that there is no other chemical reaction in the forming process of recycled micronized foam concrete except hydration reaction, and the main components in the two samples are $\mathrm{SiO}_{2}, \mathrm{Ca}(\mathrm{OH})_{2}$ and $\mathrm{CaCO}_{3}$ which are not completely hydrated.

\subsection{SEM test}

The $8^{*}$ group specimens were crushed to take small pieces of $10 \mathrm{~mm} \times 10 \mathrm{~mm} \times 10 \mathrm{~mm}$ for SEM test, and small pieces of ordinary foam concrete of the same size were taken as control. The test results are shown below.

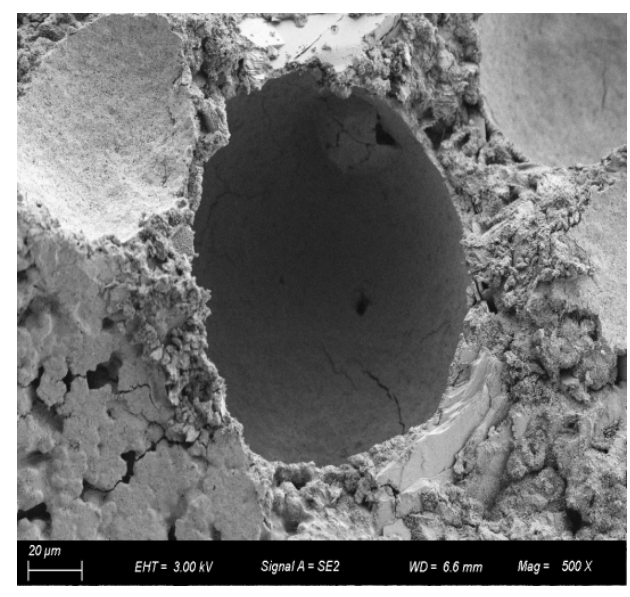

(a) $500 \times$

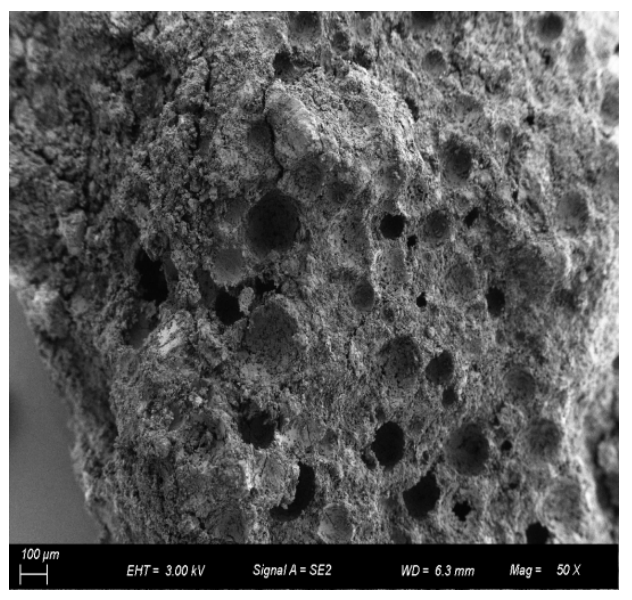

(b) $50 \times$

Figure 7. SEM photos of ordinary foam concrete hydrated at 28d 


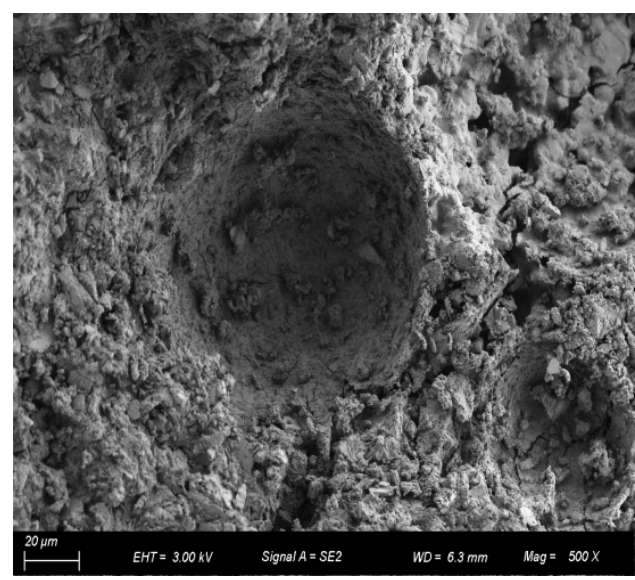

(a) $500 \times$

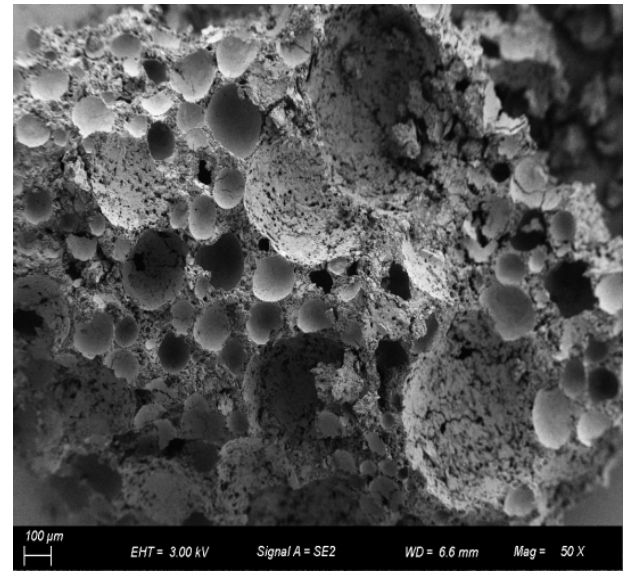

(b) $50 \times$

Figure 8. SEM photos of recycled micronized foam concrete hydrated for $28 \mathrm{~d}$

Combining Figure 7 and Figure 8, it can be found that when the magnification is $500 \times$, the pore wall of Figure 7(a) is smooth and there is no other morphological material, which indicates that the cement is completely hydrated; the pore wall of Figure 8(a) can be obviously found granular material, which is actually regenerated micronized particles. When the magnification is $50 \times$, Figure 7 (b) the pore size of the stomata is large and the foam concrete matrix is loose. Figure 8 (b) the pore size of the air pore is small and the foam concrete matrix is dense.

For both samples, the compressive strength of recycled micronized foam concrete was approximately twice that of ordinary foam concrete. From the results of SEM tests, it can be concluded that the increase in compressive strength of recycled micronized foam concrete is due to the refinement of the pores by the added recycled micronized powder, which increases the compactness of the concrete matrix.

\section{Conclusion}

In this paper, by studying the specific strength of recycled micronized foam concrete with different component material mix ratios for data processing and microscopic scanning analysis, the following conclusions can be obtained.

Through the extreme difference analysis of the orthogonal test data, the influence of foam admixture, construction waste recycled micronized powder admixture, water material ratio and HPMC admixture on the compressive strength of recycled micronized concrete is: foam admixture $>$ construction waste recycled micronized powder admixture $>$ water material ratio $>$ HPMC admixture.

Using the efficacy coefficient method, the level of recycled micronized foam concrete that meets the requirements of light weight and high strength is A2B3C4D5, i.e. the optimal mix ratio is 4\% foam admixture, $30 \%$ recycled micronized construction waste admixture, 0.6 water to material ratio and $0.07 \%$ HPMC admixture.

With the increase of foam admixture, the compressive strength of recycled micronized foam concrete gradually decreases, and the decreasing effect is very significant; with the increase of construction waste admixture, the compressive strength of recycled micronized foam concrete gradually decreases; with the increase of water-material ratio, the compressive strength of recycled micronized foam concrete first rises and then decreases; with the increase of HPMC admixture, the compressive strength of recycled micronized foam concrete gradually increases, but the increase is not large.

The regenerated micronized foam concrete only undergoes hydration reaction during the molding process; the improvement of compressive strength of regenerated micronized foam concrete from microscopic analysis is due to the refinement of pores by the added regenerated micronized powder, which increases the compactness of the concrete matrix.

\section{Acknowledgments}

This work was financially supported by the Science and Technology Research Project of Jiangxi Provincial Education Department(GJJ205301) and Nanchang University of Aeronautics and Astronautics Postgraduate Innovation Special Fund(YC2020-095). 


\section{References}

[1] Li Qiuyi, Quan Hongzhu, Qin Yuan. Recycled concrete aggregates [M]. Beijing: China Construction Industry Press, 2011.

[2] Kirubajiny Pasupathy, Sayanthan Ramakrishnan, Jay Sanjayan. Inflfluence of recycled concrete aggregate on the foam stability of aerated geopolymer concrete[J]. Construction and Building Materials, 2021, 271.

[3] Zhang Xiao-Ming, Huang Peizeng, Cui Qingyi. Research on the performance of construction waste recycled micronized foam concrete [J]. Concrete and Cement Products, 2020(05): 96-98.

[4] Shi Shiqin. Research on the thermal insulation performance of steel slag foam concrete [D]. Anhui University of Technology, 2016.

[5] Li Yingquan, Zhu Lide, Li Juli, Hu Shikai, Duan Ce, Wang Xiaofan. Design of foam concrete mix ratio [J]. Journal of Xuzhou Engineering College (Natural Science Edition), 2011, 26(02): 1-5+90.

[6] Yang Fanxuan, Shi Minghui, Niu Yangyang, Wang Yao, Jiang Junyi, Zhang Jiaxuan, Yin Guangsheng. Research on foam concrete proportion based on orthogonal test [C]. Proceedings of the 28th National Academic Conference on Structural Engineering (Volume III). 2019.

[7] Yu Junyan. Research on the foam lightweight soil roadbed for Binlai Expressway reconstruction and expansion [D]. Shandong University, 2018.

[8] Gao Yunyan. Orthogonal and regression test design methods [M]. Beijing: Metallurgical Industry Press, 1988. 